\title{
Active Control of Structures
}

\section{André Preumont}

Université Libre de Bruxelles, Brussels

\section{Kazuto Seto}

Nihon University, Japan

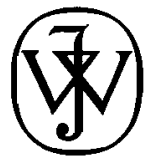

A John Wiley \& Sons, Ltd, Publication 


\section{Contents}

About the Authors $\quad$ xi

Preface xiii

Acknowledgements $\quad \mathbf{x v}$

1 Active Damping $\quad 1$

1.1 Introduction 1

1.1.1 Why Suppress Vibrations?

1.1.2 How can Vibrations be Reduced? 2

1.2 Structural Control $\quad 2$

1.3 Plant Description 3

1.3.1 Error Budget 4

1.4 Equations of Structural Dynamics 6

1.4.1 Equation of Motion Including Seismic Excitation 6

$\begin{array}{lr}1.4 .2 \text { Modal Coordinates } & 8\end{array}$

1.4.3 Support Reaction, Dynamic Mass 10

1.4.4 Dynamic Flexibility Matrix 12

1.5 Collocated Control System $\quad 15$

1.5.1 Transmission Zeros and Constrained System 18

$\begin{array}{ll}\text { 1.5.2 Nearly Collocated Control System } & 20\end{array}$

1.5.3 Non-Collocated Control Systems 21

1.6 Active Damping with Collocated System 24

1.6.1 Lead Control 25

1.6.2 Direct Velocity Feedback 29

1.6.3 Positive Position Feedback 31

1.6.4 Integral Force Feedback 35

1.6.5 Duality between The Lead and IFF Controllers 44

1.7 Decentralized Control with Collocated Pairs 46

1.7.1 Cross-Talk 46

1.7.2 Transmission Zeros (Case 1) 47

1.7.3 Transmission Zeros (Case 2) 52

References 55 
2 Active Isolation $\quad 57$

2.1 Introduction 57

2.2 Relaxation Isolator $\quad 60$

2.2.1 Electromagnetic Realization 62

2.3 Sky-hook Damper 64

2.4 Force Feedback $\quad 66$

2.5 Six-Axis Isolator $\quad 69$

2.5.1 Decentralized Control 73

2.5.2 Leg Design 76

2.5.3 Model of the Isolator $\quad 80$

2.5.4 Six-Axis Transmissibility $\quad 82$

2.6 Vehicle Active Suspension $\quad 89$

2.6.1 Quarter-Car Model 91

$\begin{array}{lll}2.7 & \text { Semi-Active Suspension } & 106\end{array}$

2.7.1 Semi-Active Devices 106

2.7.2 Narrow-Band Disturbance 107

2.7.3 Quarter-Car Semi-Active Suspension 108

References 113

3 A Comparison of Passive, Active and Hybrid Control 117

$\begin{array}{ll}3.1 \text { Introduction } & 117\end{array}$

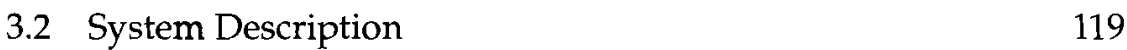

$\begin{array}{ll}\text { 3.3 The Dynamic Vibration Absorber } & 120\end{array}$

3.3.1 Single-d.o.f. Oscillator $\quad 120$

3.3.2 Multiple-d.o.f. System 123

3.3.3 Shear Frame Example 124

3.4 Active Mass Damper $\quad 126$

3.5 Hybrid Control 131

3.6 Shear Control 133

3.7 Force Actuator, Displacement Sensor $\quad 135$

3.7.1 Direct Velocity Feedback 136

3.7.2 First-Order Positive Position Feedback 137

3.7.3 Comparison of the DVF and the PPF 138

3.8 Displacement Actuator, Force Sensor 140

3.8.1 Comparison of the IFF and the DVF 142

References 144

4 Vibration Control Methods and Devices $\quad 147$

4.1 Introduction 147

4.2 Classification of Vibration Control Methods 148 
4.3 Construction of Active Dynamic Absorber

4.4 Control Devices for Wind Excitation Control in Civil Structures

4.5 Real Towers Using the Connected Control Method

4.6 Application of Active Dynamic Absorber for Controlling Vibration of Single-d.o.f. Systems

4.6.1 Equations of Motion and State Equation

4.6.2 Representation of a Non-Dimensional State Equation

4.6.3 Control System Design

4.6.4 Similarity Law between Dimensional and Non-dimensional System

4.6.5 Analysis of Vibration Control Effect

4.6.6 Experiment

4.7 Remarks

References

5 Reduced-Order Model for Structural Control

5.1 Introduction

5.2 Modeling of Distributed Structures

5.2.1 Equation of Motion for Distributed Structures

5.2.2 Conventional Modeling of Structures

5.4 The Lumped Modeling Method

5.4.1 A Key Idea for Deriving a Reduced-Order Model

5.4.2 Relationship Between Physical and Modal Coordinate Systems

5.4.3 Modification of Normalized Modal Matrix

5.5 Method of Equivalent Mass Estimation

5.5.1 Meaning of Equivalent Mass

5.5.2 Eigenvector Method

5.5.3 Mass Response Method

5.6 Modeling of Tower-like Structure

5.6.1 Two-d.o.f. Model

5.6.2 Dimension and Dynamic Characteristics of the Tower-Like Structure

5.6.3 Calculation of Parameters of Two-d.o.f. Model

5.6.4 Comparison between the Distributed Parameter and Two-d.o.f. Systems 
5.7 Modeling of Plate Structures 203

5.7.1 Dimensions of a Plate Structure 203

5.7.2 Three-d.o.f. Model 206

5.7.3 Calculation of Parameters of the Three-d.o.f. Model 207

5.7.4 Comparison between Real System

and Three-d.o.f. Systems 208

5.8 Modeling of a Bridge Tower 209

5.8.1 Dimensions of a Scaled Bridge Tower 209

5.8.2 Construction of a Four-d.o.f. Model 210

5.8.3 Calculation of Parameters of the Four-d.o.f. Model 212

5.8.4 Comparison between Real System and Four-d.o.f. Systems 213

5.9 Robust Vibration Control for Neglected Higher Modes 217

$\begin{array}{ll}5.10 \text { Conclusions } & 217\end{array}$

References $\quad 219$

6 Active Control of Civil Structures 221

6.1 Introduction 221

6.2 Classification of Structural Control for Buildings 222

6.3 Modeling and Vibration Control for Tower Structures $\quad 222$

6.3.1 One-d.o.f. Model 222

6.3.2 Two-d.o.f. Model for Tower-Like Structures and Its LQ Control

225

6.3.3 Three-d.o.f. Model for Broad Structures and Its $H_{\infty}$ Robust Control

228

6.3.4 Four-d.o.f. Model for Bridge Tower and Spillover Suppression Using Filtered LQ Control

6.4 Active Vibration Control of Multiple Buildings

Connected with Active Control Bridges in Response to

Large Earthquakes

6.4.1 Construction of Four Model Buildings

6.4.2 Characteristics of the Tower Structures

6.4.3 Reduced-order Model of the Four Tower Structures

Connected by Four Actuators

6.4.4 Control System Design

6.4.5 Simulated Results of Seismic Response Control 257

6.4.6 Experiment

6.5 Vibration Control for Real Triple Towers Using CCM 264

6.5.1 Outline of the Triple Towers 264

6.5.2 Modeling of Towers 
6.5.3 Control System Design 266

6.5.4 Simulation of the Triple Towers Using CCM 269

6.5.5 Realization of the CCM 270

6.6 Vibration Control of Bridge Towers Using a Lumped

Modeling Approach 274

6.6.1 Vibration Problem of Bridge Towers Under Construction 274

6.6.2 Controlled Object and Its Dynamic Characteristics $\quad 277$

6.6.3 Five-d.o.f. Modeling of a Scaled Bridge Tower

Structure with a Crane Tower $\quad 278$

6.6.4 LQ Control System Design 278

6.6.5 Simulations 283

6.6.6 Experiments 283

6.6.7 $H_{\infty}$ Robust Control 286

6.7 Conclusion $\quad 290$

References $\quad 291$

Index

293 